\title{
Global Leadership in a University Setting
}

Maryam Hassanzadeh

H/p: 011 23848667; maryam.hassanzadeh@outlook.com

Abu Daud Silong, PhD

Ali Mohammad Hossein Zadeh

Hajar Ghadirian

\section{Sara Kasmaienezhadfard}

Department of Professional Development and Continuing Education Faculty of Educational Studies, Universiti Putra Malaysia

Doi:10.5901/mjss.2016.v7n2p353

\begin{abstract}
What is global leadership? How can we develop global leadership for a university? This study was conducted using the qualitative approach through in-depth interviews of eight selected top leaders in a selected university. Based on the in-depth interviews, the findings discussed are as follows; Global leadership is related to diversity. Global leaders need to be developed with additional competencies to lead a university and to be able to compete worldwide. Global leadership has to operate in diverse situations. This means that a global leader has to understand different cultures, different ideas and different beliefs. So a global leader has to understand leading in diversity, which requires a different set of competencies. These include attitudes, skills and knowledge. This study is significant because it fills a gap in current knowledge regarding the experience that leaders perceived to be important in understanding and developing global leadership.
\end{abstract}

Keyword: Global leadership, global leadership competencies, global leadership and diversity, global leadership development.

\section{Introduction}

For the past century or so research in leadership was focused more on the traits, behavior and situational leadership theories. Traits theory focused on identifying characteristics of leaders. Stogdill (1948) identified intelligence, alertness, insight, responsibility, initiative, persistence, self-confidence and sociability as traits for effective leadership. Again in 1974 he identified similar traits plus some other traits such as achievement, cooperativeness, tolerance and influence. Other researchers noted other traits in their studies, for example, Bass (1990), Northouse (1997) and Madinah Mohamad and Abu Daud Silong (2008).

Behavior theory on the other hand examined different styles and roles of leadership. Behavior studies included those conducted by researchers from University of lowa, Michigan University and Ohio University (Lewin \& Lippit, 1938; Hemphill \& Coons, 1957; Likert, 1961), whereas situational leadership was proposed by Fiedler (1967), House (1974) and Hersey-Blanchard (1988). In situational leadership it is suggested that to be effective, leaders must match leadership style with situations. More recent work also includes the integrative theory such as transactional-transformational and servant leadership. Integrative theories looked to leadership ideas focusing on holistic leadership ideas.

However, most recent work on leadership brings new ideas to the debate and global leadership is one of the key ideas being proposed (Ducker, 2012). It is the leadership idea for the future.

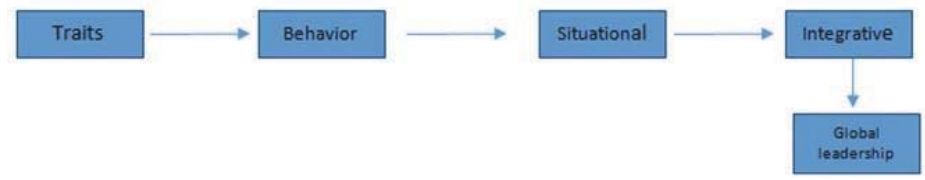

Figure 1. Development of leadership theories and ideas 


\section{Literature Review}

To summarize, leadership theories began with the traits theory followed by behavior, situational and integrative theories. Going to the future the idea of global leadership is proposed (Figure 1). However, global leadership is a new concept which began to appear in the nineties. It arose due to the phenomena of globalization. Because of this process there were new demands for organizations, so the idea of leadership changed from just being a domestic leader to be a global leader. However, the concept of global leadership was not very well-understood or developed, and required further research (Turnbull, 2009; Mendenhall et al., 2008; Ducker, 2012) Global leadership was initially understood to be a leader with a larger job scope that includes the global stage with different geographical boundaries. (Caligiuri, 2006; Spreitzer, McCall, \& Mahoney, 1997; Caligiuri \& Tarique, 2009; Suutari, 2002; Ding, 2013)

On the other hand, as the topic was further debated the concepts of domestic leadership and global leadership were proposed. Thus there was a need to differentiate the two types of leadership. There were differences that needed to be highlighted when a person assumed the role of global leadership. For example, to be a global leader a person needs added competencies to be an effective leader (Mendenhall et. Al., 2008; Javidan et al., 2006; Osland \& Brid, 2005; Ding, 2013; Caligiuri 2013), but the question is "What are those competencies?" This also requires more research before an adequate answer can be approaching.

Another key idea related to global leadership in the literature that appeared most recently is diversity (Conger et al., 2012; Ding, 2013; Freshwater 2014). Global leadership has to operate in diverse situations. This means that a global leader has to understand different cultures, different ideas and different beliefs. So she/he has to understand leading in diversity, which requires a different set of competencies such as attitudes, skills and knowledge.

Diversity is not only about differences in color and gender, but also about people with different interpretations of the act. The importance of exchanging information leads people to work together but those who work together as a team face challenges such as differences in language, values, beliefs, cultures, and religions. Thus it is critical for global leaders to understand how their behaviors appear in the eyes of their followers (Maryam Hassanzadeh et al., 2015: 162).

"Global leadership is a recent phenomenon. It began to appear in the literature in early 1990s" (Ducker, 2012). Maryam Hassanzadeh (2015) mentioned "global leadership can be defined as a leader who operates on a global stage with the global mindset in an environment that is complex and diverse with competencies such as networking and flexibility" (p. 17). Freshwater (2014) also believed global leaders recognize the aspirational, innovative and creative perspectives that have both driven the agenda to date, these being the legacy issues, and the drive towards transforming and building on those successes. Ding, H. (2013) defined global leader as someone who has unique skills to lead diverse employees and understand different countries' legal systems and business operation. On the other hand Conger \& O'Neill's (2012: 53) perspective about global leadership is focused on boundaries. "Basically, the term refers to an organization's leadership talent who work across geographic and cultural boundaries". However, the idea of global leadership is not well researched yet. Some research has been conducted on the topic in the West since the 1980s. There are no similar studies that have been conducted in Malaysia thus far. Also there are no similar studies being conducted related to global leadership and a reputable university.

This research examines global leadership in the context of a reputable university in Malaysia, which intends to be a developed nation by the year 2020. Thus Malaysia needs an innovation-driven knowledge economy to achieve higher income in the future. Talent development is one of the keys to developing human capital with the necessary knowledge and skills. Thus, investment in human capital is the most important strategy in achieving Vision 2020. When we talk about human capital, universities are an important part of the efforts. We need a reputable university that is ranked among the top 100 in the world. In a globalized world, Malaysian universities need to compete with others worldwide, so leadership is a key factor in achieving world recognition. As such, Malaysian universities have to operate with a global environment such as having foreign staff and students, adequate funding, excellent research, teaching and learning. This means that Malaysian universities need a new kind of leader such as a global leader to lead a reputable university.

This study is significant because it fills a gap in current knowledge regarding the experience that leaders report to be important in understanding global leadership and its development. There is a lack of information in research about understanding global leadership and also developing domestic leaders as global leaders to lead reputable universities. Therefore, the findings of this study can contribute to a better understanding of the phenomenon of global leadership, especially from the perspective of developing countries. The findings of the research will also contribute to improving global leadership practices and policies in Malaysian universities. 


\section{Methodology}

This study was conducted using the qualitative approach through in-depth interviews of eight selected top leaders in a selected reputable university in Malaysia. This researcher has received strong support from various parties in the university to conduct this study. The nature of this study and the research questions asked are suitable for the qualitative approach adopted for this study. This interview was conducted with past and present VCs and two past Deputy VCs of selected university. The participants were contacted for their agreements to be involved in the research. The date, time and place of interviews were decided through consultation with the participants. Each interview lasted between one and two hours and all the interviews were recorded with the permission of the participants. The interviews were conducted using an interview guide.

In conducting data analysis the researcher considered it as a process of giving meaning to the data collected. In the process the researcher organized, structured and interpreted the meanings of the data collected. It involved synthesis, data reduction, and interpretation of what the participants had said and also what the researcher observed. The researcher's meaning and understanding of those data constitute the findings of this research.

Data were analyzed manually. Findings were categorized into themes and sub-themes. Data analysis was carried out simultaneously with the data collection phase. Interviews were transcribed verbatim, including pauses, laughs, and other remarks. The analysis started as soon as transcribing was completed. The categories and themes were linked to each other so as to build a logical chain of evidence. In this study the validity and reliability were ensured through triangulation, peer examination, audit trail and thick data description.

\section{Findings}

Based on the in-depth interviews, the findings discussed are as follows:

(1) Diversity and globalization as a cause of global leadership, (2) Global leaders need some additional competencies, (3) To be effective global leaders need to develop additional competencies, (4) leading a university by global leadership.

\subsection{Diversity and globalization as a cause of global leadership}

The global leaders in this study highlighted globalization and diversity as one of the global leadership themes. They developed their capabilities to fulfill their roles as global leaders to work effectively in diverse environments. They gained important new insights, perspectives and skills in the areas of cultural attitudes, cultural skills and cultural knowledge. The cultural attitudes described by the global leaders in this study included understanding the feelings of others (Emotional Intelligence (EQ)); sensitive to the different ethics, sub-ethics and norms; willingness to work in a team, establish linkage, talking to people and accommodating women; readiness to adapt new ways and accept feedback; and lastly, the need for flexibility of global leaders.

This study identified cultural skills such as cultural intelligence (Cultural Intelligence (CQ)); establishing terms of behavior for code switching, communication, adapting to the new culture, using cultural gap potential, localizing human resource to the local context, applying cultural knowledge and functioning in diverse environment; having integration for group decision making; building organizational culture based on various cultures; balancing between diverse cultures and networking through social media.

Ultimately, global leaders in this study described cultural knowledge as self-awareness, cultural awareness and problem awareness; understanding human potential; knowing cultural influences; understanding cultural elements and learning competencies. The common element among all global leaders in this study is to perform in diversity. These include diversity as the cause of globalization, which is a big challenge for global leaders. To be an effective leader in a diverse environment, global leaders need EQ to understand the feelings of others; CQ to appreciate the differences and awareness of culture. Thus, instilling harmony among cultures in a multi-cultural organization is the art of global leaders.

\subsection{Global leaders need additional competencies}

The participants in this study described many competencies as being important for them to fulfill their roles on the global stage. These competencies are categorized according to attitudes, skills and knowledge. They described attitudes as personality and behavior that include being open-minded, idealistic, adaptable and fearless. Open-mindedness is being able to appreciate differences, and accept different ideas. To the participants an open-minded person is not only a good 
listener but also one who is prepared to select the best idea even if it is not his or her own idea. They also practiced their adaptability skills to fit unfamiliar environments. And most of them strongly believed their willingness to work in diversity and living far from their family that can help them to perform effectively in their organizations. And to them not only willingness but also fearlessness helped them to fulfill their global leadership roles.

Besides attitudes they also developed their global leadership skills such as experiences, global sensitivity, global critical thinking, working in teams and leadership skills. All the participants in this study mentioned the importance of experience. They discussed not only working experiences but also their early experiences in life that shaped their personalities and their beliefs. All participants in this study had experiences of overseas education. They explained not only the overseas education but also their country's environment developed them as individuals appreciative of differences. They explained that very early in their life they understood the inevitability of different people having different religions, beliefs, colors, and languages but all can live together in harmony by respecting each other. They developed their global sensitivity skills by working in multicultural teams. The participants in this study when sharing their experiences about global leadership competencies mentioned that the global leader is still first and foremost a leader. Thus they need to have leadership competencies. Besides, all global leadership skills they were also open to learning all other leadership skills.

The participants mentioned that they developed their cultural knowledge such as self-awareness and multicultural awareness and technological knowledge. To them self-awareness is of the same importance as multicultural awareness. They believed self-awareness helped them to understand the differences. They also improved their knowledge of new technology, but mentioned having knowledge about technology does not mean that they have to be professional programmers but the awareness of how this new technology can affect their organizations and how they can perform effectively by using the new technology in their organizations.

\subsection{To be effective global leaders need to develop additional competencies}

The participants in this study developed their capabilities needed to effectively play their roles by developing their abilities, skills and knowledge. They found that to be effective on the global stage they needed to be innovative, positive, willingness and possessing a global mind-set. Some people can be successful and effective at home, but as soon as they are out of their countries they can only perform as a "village champion". They do not know how to handle diversity which is critical for global leaders. They described a global mind-set as an open-mindedness and that allows them to think beyond their own people, and beyond familiar environments. Going from local to the global stage needs a strategy, plan and thinking both at the global and local levels. They believed by having an open-mind they would not be surprised by meeting new people. They explained leaders need to be open-minded, think globally in order to understand differences in people, and also differences in the environment they find themselves in from time to time. They noted that with an open mind-set they could accept their mistakes and when they were aware of their faults, it was easier for them to find the solutions.

While engaging themselves in developmental experiences, the participants in this study gained skills such as collaborating, linking and networking with others. They paid due importance to planning and strategizing as well as networking with the university's international alumni and encouraged the development of relationships between current students and alumni and a sense of attachment to their alma mater. Global leaders must meet people, entertain people, and get people to know themselves. They revealed that while they were into networking they also had to keep the linkages. Linkages and networking helped them to analyze each other's strategies and plans. Thus, they could make a "shortcut" from their colleagues' success by collaborating with them. They also practiced working as a group with their staff. They noted people in organizations needed to feel comfortable, to open up and share their problems, otherwise their problems would remain unsolved. To accomplish this they needed to trust their leaders and global leaders must build that trust by engaging in effective communication. They repeated the need to know about ourselves first, where we come from, and what are our norms; who our heroes are, and then we need to be aware of the host country's culture as well. It may take a long time to learn a new culture, but it is vital for global leaders. They developed their skills and knowledge by traveling all over the world, attending international conferences, having international assignments and participating in international training and programmes.

\subsection{Leading a university through global leadership}

The participants in this study held top leadership positions in university. Thus, they had good understanding and experiences about the structure and quality of a reputable university. They described a reputable university as an 
institution with academic excellence, adequate finance and diverse culture. The academic excellence described by participants in this study included academic achievement, having a young group of researches, focusing on the strengths of the university, be able to attract talent, conducting research for the government, making "shortcut" by looking to the reputable universities' success, systematic planning, having an education center, exchange programs and traveling all over the world. Through their experiences in leading a research university they pointed to academic excellence as the first requirement to be a reputable university. However, it is not only excellence but it should be relevant as well. The programs and research should fulfill the needs of the nation and prepare the students to compete on the global stage. Some of the participants in this research also mentioned that the steps to start building a reputable university do not necessarily have to be taken by the top leader of the university (Vice Chancellor). It also can be started by the faculties and individuals.

On the other hand, to be a reputable university there is a need for an adequate budget. Participants in this study mentioned that finance plays a vital role in promoting a reputable university. Besides the finance, a global culture must be developed to enhance the reputation of the university in a global environment. They believed global leaders need to thrive in diversity, make research as part of university culture and implement diverse and global cultures in the university and changing the mind-set of university's people.

Participants in this study also described the competencies which they need to develop to lead a reputable university in two themes: their personal attitudes, and skills. Through their experiences in leading a reputable university they gained important attitudes such as learning from others, being flexible, being an idealist, having patience, willing to take risks and be honest with the system. They also developed the skills such as being able to create a global vision followed by local mission and action, be able to inspire others, work with universal cultures, networking and keeping linkage with others.

\section{Conclusion}

Based on the literature and findings of this paper, two major conclusions can be made related to global leadership and developing global leadership. In trying to understand global leadership, some of the key ideas from the research were discussed as follows:

There is a difference between domestic and global leadership. Some scholars believed that global leadership is just a new word that appeared in the new leadership era. Thus they did not differentiate the domestic leader from the global leader. However, from this study, it was concluded that global leadership is not the same as domestic leadership. The participants interviewed in this study shared several experiences in dealing with different groups of people. They indicated that they might not have been successful if they had continued to behave the same way when dealing with their own people. Global leaders must be aware of differences and accept others from different backgrounds.

Everyone has the potential to be a leader. So, everyone also can be a global leader in his or her area of expertise. Each of us has a different understanding of global leadership. First, a global leader is a hero or the person who is an expert in his/her chosen field. For example, if you are an experienced agriculturist, you can be a global leader in agriculture. Besides the area of expertise needed, the ability to lead a group of people is important because it helps to achieve the organization's goals. The first requirement to be labelled as a global leader is the ability to deal with different people from various backgrounds and geographical areas.

Another important idea in understanding global leadership is diversity. Most scholars define diversity as differences in language, religion, color, gender, sexual orientation, age and ability. But this can be a simple understanding about diversity. When we talk about diversity in organizations, we talk about those challenges regarding the different interpretations and understandings among members. A global leader can reward or punish a member from one country and this may not be the same for a member of another country. This is because they have different ways and meanings about motivation or punishment in their systems. Thus, the same strategy may not be effective for all groups. Also, different people have different ways in making decisions or completing their tasks. Thus, as mentioned above, diversity in organizations is not limited to simple differences in gender, age, language and religion.

Another key idea from the study is the use of the term "global mind-set". Researchers have indicated that having a global mind-set is vital to be a global leader. In other words, without a global mind-set a person cannot be a global leader. In this study it has been concluded that having a global mind-set is only an extra quality needed to be a global leader while other attitudes like EQ are more important than global mind-set. But for those leaders who want to extend their organization from domestic to the global stage, global mind-set is vital. This is because they need to see their place in comparison to others in the world. Global mind-set helps global leaders to be effective in their roles and also make the situation easy for them to work in. But this study has noted that for those companies which operate in a multicultural 
environment, and if the person wants to join as a global leader, global mind-set is just an extra quality.

As mentioned in this study, people carry their own cultural baggage into the organization. Thus, they have different sensitivities. Misinterpretation and misunderstanding can make people experience certain emotions. Global leaders must pay attention to the feelings of their followers. Therefore, emotional intelligence (EQ) is a key attitude required for global leaders.

Researchers indicated how we can develop global leadership. However in most cases they did not focus on the right person, practices and organizational needs. In this study it has been concluded that not everyone is capable of being a global leader, not all skills can be effective for developing global leaders and not all organizations see the value of global leadership practices in their organizations. Based on the analysis of the definitions of global leadership as provided in the literature and findings of this study, the conclusion is that:

\section{Global leadership "... is leadership in diversity; this means that a global leader can lead a diverse group of people."}

Researchers also concluded that based on the research: To develop global leadership, organizations need to develop global leadership competencies among their talents and special focus should be on increasing the cultural intelligence (CQ) skills and emotional intelligence (EQ) attitudes.

\section{Recommendations}

This research explored global leadership from the experiences of top level university leadership. Based on the findings, the following recommendations are forwarded to various parties for improving global leadership practices in university:

1. Recommendations to Ministry of Education (higher education) to develop more systematic training for university leaders in the area of global leadership. The research indicated that there is a need for leaders to have additional competencies when they assume the role of global leadership. Most of the training has so far been more focused on training domestic leadership. But when they move from domestic to global leadership they have to learn additional competencies.

2. To develop training modules based on the new competencies identified - the research identified that the key to be an effective global leader for a reputable university is to develop cultural intelligence. This means that those involved in global leadership must have the ability to understand the differences of people from various backgrounds and appreciate them.

3. To identify the potential domestic leader to be developed into a global leader. They should be exposed to global assignments and given the proper training on global leadership.

4. A reputable university needs to develop global leaders to enable the university to compete worldwide.

\section{References}

Abu Daud Silong, Madinah Mohamad, Zaharah Hassan and Ismi Ariff. (2008). Changing roles and competencies for effective public sector leadership. Journal Pengurusan Awam, 7 (1): 27-46

Bass, B. M. (1990). Bass \& Stogdill's Handbook of leadership: Theory, research and managerial application (3rd Ed.). New York: The Free Press.

Caligiuri, P. (2006). Developing global leaders. Human Resource Management Review, 16: 219-228.

Caligiuri, P. (2013). Developing culturally agile global business leaders. Organizational Dynamics, 42: 175-182.

Caligiuri. P., \& Tarique. I. (2009). Predicting effectiveness in global leadership active. Journal of World Business, 44: 336-346.

Conger, J. A. and O'Neill, C. (2012). Building the bench for global leadership. People \& Strategy, 35(2): 53-57.

Conger, J. A and O'Neill, C., (2012). Building the bench for global leadership, People and Strategy, 35 (2): 53-57.

Ding Hui. (2013). Virtual global leadership model: exploratory research of leadership. Proceedings of 7th Global Business and Social Science Research Conference. Radisson blu hotel, Beijing, China.

Ducker, C. (2012). Global leadership - grasping a slippery term. Encounters Mission Journal, 39: 1-9.

Fiedler, F.E. (1967). A theory of leadership effectiveness. New York: McGraw-Hill.

Freshwater, D. (2014). Board editorial: The challenge of global leadership: managing change, leading movement. Journal of Research in Nursing, 19 (2): 93-97.

Hemphill, J.K., and A. E. Coons. (1957). Development of the leader behavior description questionnaire. In R. Stogdill and A. Coons,

(Eds.,), Leader Behavior: Its Description and Measurement. Columbus, Ohio: Bureau of Business Research.

Hersey, P., and Blanchard, K.H., (1988). Management of organizational behavior. Englewood Cliffs, NJ: Prentice Hall.

House, R.J, and Mitchell, T.R. (1974). Path-goal theory of leadership. Contemporary Business, 3 (Fall), 81-98.

Javidan, M., House, R., Dorfman, P., Hanges, P and Sully de Luque, M. (2006). Conceptualizing and measuring cultures and their 
consequences: a comparative review of GLOBE's and Hofstede's approaches. Journal of International Business Studies. 39: 897-914.

Lewin, K., and R. Lippit. (1938). An experimental approach to the study of autocracy and democracy: A preliminary note. Sociometry, 1: 292-300.

Likert, R. (1961). New patterns of management. NY: McGraw-Hill.

Madinah Mohamad., Abu Daud Silong., Azimi Hamzah. and Zaharah Hassan. (2008). Effective leadership among Committee Members of Neighborhood Associations in Malaysian community. European Journal of Social Sciences, 7(1): 147-159

Maryam Hassanzadeh, Abu Daud Silong, Azizan Asmuni, Nor Wahiza Abd Wahat, (2015). Global Leadership and Diversity. Journal of Educational and Social Research. 5(3): 161-168.

Maryam Hassanzadeh, Abu Daud Silong, Azizan Asmuni, Nor Wahiza Abd Wahat, (2015). Developing Effective Global Leadership. Journal of Educational and Social Research. 5(3): 15-24.

Mendenhall. M. E, Osland. J. S, Bird, A. Oddou, G. R., \& Maznevski, M. L (2008). Global leadership: Research, practice, and development. London and New York: Routledge.

Northouse, P. G. (1997). Leadership theory and practice. Thousand Oaks, CA: Sage Publications

Osland, J. S \& Bird, A. (2005). Global leaders as experts. In Mobley, W. H., \& Weldon, E. (Eds.), Advances in global leadership 4: 123142. Oxford. UK: Elsevier.

Spreitzer, G. M, McCall, M. W. Jr., \& Mahoney, J. (1997). The early identification of international executive potential. Journal of Applied Psychology. 82(1): 6-29.

Stogdill, R.M., (1948). Personal Factors Associated with Leadership: A survey of the Literature.

Suutari, V., (2002). Global leader development: An emerging research agenda. Career Development International, 7(4): $218-233$.

Turnbull, Sharon (2009), "Worldly' leadership for a global world," in Harvey, Michael and Barbour, JoAnn Danelo, eds. (2009), Global Leadership: Portraits of the Past, Visions for the Future, Maryland: International Leadership Association, pp.82-94 